\title{
The OCEAnOgRaphy Society: READY FOR NEW ACTIVITIES
}

\author{
By D. James Baker, President
}

\begin{abstract}
I AM HONORED to be elected as the first President of The Oceanography Society, and I extend congratulations on behalf of the entire Society to the newly elected President-Elect, Arnold Gordon, and to the
\end{abstract}

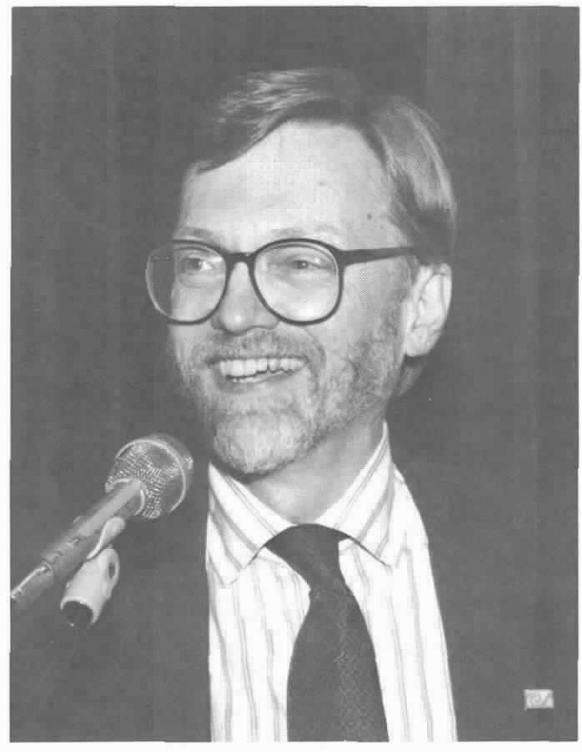

D. James Baker

members of the first Council of the Society: Penny Chisholm, Curt Collins, Cindy Lee, Tom Rossby, Connie Sancetta and Stan Wilson. Thanks are due to this group who have committed to working with the Society in its formative years, and to those who agreed to be on the ballot but who did not win. We are all looking forward to working with the new Council. This was the Society's first election; we had more than $50 \%$ of our members vote, which is an excellent turnout. The League of Women Voters counted the ballots, ensuring that there was no conflict of interest involved.

We owe the launching of the Society to the Interim Council who have been fully dedicated to their work: Dave Brooks, who has made Oceanography Magazine an inter- nationally recognized medium of communication for the field; Stan Wilson, who, more than anyone, is responsible for the success of the Inaugural Meeting; Chris Mooers, who has worked hard over plans for the next meetings; Neil Andersen, who has acted as Treasurer and Chairman of the Nominating Committee; Mel Briscoe, who has been our Secretary and the person responsible for the various items with the Society logo that were sold at the meeting (some are still available); Dave Schink, who began the long process of planning for Society meetings in general; and Leonard Johnson, who has been a source of strength and help in all of the Interim Council activities. Kudos to all for a job well done.

As we move to a more formal structure for our Council and for our office staff, special thanks for their hard work over the past eighteen months goes to our volunteers: Carol Andersen, Emily Baker, Dick Vetter and those members of the Joint Oceanographic Institutions' staff who have helped in many ways: Rebecca Grimes, Ron Tipper, Frank Eden, Jack Clotworthy, Penny Peters, Peter Dunkelberger, Allison Burns and Andrea Johnson. Thanks also to Nancy Schiffman, who has provided office support during these initial months, and to Yale Schiffman of the American Meteorological Society, who provided much useful advice and help on meeting organization.

Serving as Interim President has given me some ink ling of what the job is all about, but I hope that the next two years will see us make real progress towards the establishment of our Society as an integrating factor for the field as a whole - to help us come together as professionals in a scientific discipline and also to promote and publicize the importance of ocean science. The many activities planned have been listed in earlier issues of the magazine; now it is time to get some of these accomplished.

For those of you who were at the Inaugu- ral Meeting, I am sure that you share my view that there was a special feeling of excitement and camaraderie as the speakers shared their enthusiasm about their research. The interdisciplinary aspect of having all speakers talk to one audience worked well; Rana Fine and her Program Committee are to be congratulated for their choice of speakers. In my view, the meeting could not have gone better, especially when we consider the very short lead time and the need to make many decisions without being able to consult widely. Special thanks are due to the co-sponsoring societies, the National Science Foundation (NSF), National Aeronautics and Space Administration (NASA), and Scientific Committee on Oceanic Research (SCOR) for providing support for students and scientists from developing countries to attend the meeting, and to Annette Najjar and E. H. Pechan \& Associates, Inc., for providing a variety of meeting support services.

With the magazine launched, a successful meeting accomplished, a newly elected Council and Officers, formally adopted ByLaws, and a winning $\operatorname{logo}$, the Society is ready to serve the oceanographic community. In previous issues of the magazine, I have talked about possible activities of the Society. Now we are ready to embark on a number of these. It is our plan to distribute a questionnaire to the membership asking for your priorities for the scientific, professional, and educational activities for the Society. Please take the time to answer; we need your input.

In the meantime, we have already begun planning for our next meeting which will take place in March of next year in Washington, D.C. This meeting will be a forum focused on education of Congressional policy-makers, both members and staff who are so important in determining national priorities. The meeting will be a three-day affair and will be joint with the new Council 
on Ocean Affairs that represents a broad spectrum of oceanographic institutions. One day will be devoted to Society business. one day to the Congressional Forum, and one day to the affairs of the Council on Ocean Affairs. Ed Frieman. Director of Scripps Institution of Oceanography, has agreed to chair the Program Committee for this meeting.

We also plan to establish a series of awards and recognition for scientific achievement, not limited to but with a special emphasis on young scientists and students. Early recognition of outstanding work is an important feedback to a young person who wants to develop a career, and the Society can provide such recognition. We hope to develop a full range of awards for recognition of achievement.

The Society has been funded to provide support for educational activities by NSF, NASA and Office of Naval Research (ONR). Both NSF and NASA have provided funds for support of the next meeting of academic deans of oceanography that will take place this fall. ONR has provided support for the publishing of a booklet showing career opportunities for disabled persons in oceanography. We hope to make this the beginning of a series of career booklets. At the Inalugural Meeting. Sue Weiler chaired a meeting on the issues faced by dual-career couples. This could also be a topic that the Society helps develop. We hope to broaden the membership to make it as international as possible. At the
Inaugural meeting, eight countries outside the US were represented: Australia, Brasil. Canada, France, Germany. Korea, Mexico, Norway and Portugal. The support of the Society by international groups such as SCOR and International Association for the Physical Scicnces of the Ocean is welcomed, and we hope that it can be mutually beneficial. Charlie Miller has agreed to be Chairman of our Membership Committee and will be contacting the membership for suggestions.

We are planning a major mailing of Society information to oceanographers outside the US in order to broaden our membership as much as possible. The field of oceanography is international, and the Society should reflect this. We also are looking to ways to affiliate and work with national societies related to ocean science. particularly in exchange of publications like Oceanography Magazine.

For me. the meeting was the inspirational point of a recent round of experiences that might be worth recounting. In July, I attended the biennial Assembly of the Intergovermmental Oceanographic Commission (IOC) in Paris. There was a strong sense of renewed commitment to the IOC from its member countries because of the world-wide recognition of the need for documenting. understanding and predicting global change. The new opportunities offered by this recognition could help to put in place the programs that we have all been working for.
Early in August. I gave a series of lectures in Brazil for the United States Information Agency. I was struck by the growing interest. desire and enthusiasm for a strong ocean program in that country: in spite of its economic and social problems. Brazil has a vital science enterprise that could have a major impact on all aspects of life. There was a strong interest there in developing joint programs with The Oceanography Society. Then, at the end of August. I came to Monterey, where themes of ocean science were interspersed with advice and wisdom from the long-time leaders of the field.

I found this total experience inspiring and exciting. and it seems to me to sum up our challenges and opportunities in ocean science today: an understanding of the environment is more important than ever: the necessary technology is mostly available and ready to be used: and there is a complete cast of characters-the occanographic community-ready to make things happen.

As your president, I am prepared to work with you and to make things happen. In September, the Council had its first meeting, and we set a course of action for the future. As we go, we will look to you. the members. for advice and support. Please help: as I urged at the meeting. enroll your colleagues in the Society. We re looking forward to working with a broad community in the Society for the ocean sciences. ב

\title{
Measurement of Photosynthetic Response to Euphotic Zone Physical Forcing
}

\author{
By Gary J. Kirkpatrick, Thomas B. Curtin, Daniel Kamykowski, and Michael Feezor
}

\begin{abstract}
$\mathrm{W}_{\mathrm{E}}$ innovative biophysical in situ measurement system to investigate the role of vertical motion in the photosynthetic response of
\end{abstract}

Gary J. Kirkpatrick and Ditniel Kamykowsk, Bor 8208, Marine. Earth and Amospheric Science, North Carolina State Liniversity. Raleigh. NC 27695-8208; Thomas B. Curtin. Office of Naval Rescarch. Code 1125AR. 800 N. Quincy. Arlington. VA 22217: Michael Feezor, Electronic Design Consultants, Inc.. P.O. Box 2008. Chapel Hill, NC 27514.

Editor's Note:

This is the abstract of the winning student poster at TOS's Inaugural Meeting phytoplankton within the upper mixing layer of the ocean. The two elements of the system are highly alutomated ensembles of sensors and control mechanisms integrated to obtain coincident measurements of photosynthesis and velocity/density. The scales of physical motion addressed locally range from one centimeter to one meter and ten hertz to ten days. To cover larger spatial scales such systems can be nested in arrays. Velocity is sensed electromagnetically with electrodes distributed to resolve a wave number/frequency spectral window thought to be important in defining plankton trajec- tories. The self-contained, in situ photosynthesis device acquires multiple rate estimates from a contained culture. Photosynthetic response is obtained on time scales from approximately five minutes to twentyfour hours by controlling the range of $\mathrm{pH}$ and dissolved oxygen within the culture. A principal objective of the measurement is to determine the coherence between physical forcing and phytoplankton response. Recent prototype field data are presented to demonstrate performance and compare output from this system with standard techniques of photosynthesis measurement. $\square$ 